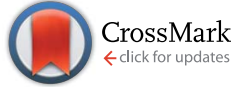

Cite this: J. Mater. Chem. A, 2014, 2, 16135

Received 18th April 2014

Accepted 7th June 2014

DOI: $10.1039 / c 4 t a 01933 d$

www.rsc.org/MaterialsA

\section{Effects of oligothiophene $\pi$-bridge length on physical and photovoltaic properties of star-shaped molecules for bulk heterojunction solar cells $\uparrow$}

\author{
Jie Min, ${ }^{\text {*a }}$ Yuriy N. Luponosov, ${ }^{\mathrm{b}}$ Derya Baran, ${ }^{a}$ Sergei N. Chvalun, ${ }^{\text {bc }}$ \\ Maxim A. Shcherbina, ${ }^{\text {bd }}$ Artem V. Bakirov, ${ }^{c}$ Petr V. Dmitryakov, ${ }^{c}$ \\ Svetlana M. Peregudova, ${ }^{e}$ Nina Kausch-Busies, ${ }^{f}$ Sergei A. Ponomarenko, ${ }^{b g}$ \\ Tayebeh Ameri ${ }^{a}$ and Christoph J. Brabec ${ }^{\text {ah }}$
}

\begin{abstract}
The preparation of four different star-shaped donor (D)- $\pi$-acceptor (A) small molecules (N(Ph-1T-DCN$\mathrm{Me}_{3}, \quad \mathrm{~N}(\mathrm{Ph}-2 \mathrm{~T}-\mathrm{DCN}-\mathrm{Me})_{3}, \quad \mathrm{~N}(\mathrm{Ph}-2 \mathrm{~T}-\mathrm{DCN}-\mathrm{Hex})_{3}$ and $\left.\mathrm{N}(\mathrm{Ph}-3 \mathrm{~T}-\mathrm{DCN}-\mathrm{Hex})_{3}\right)$ possessing various oligothiophene $\pi$-bridge lengths and their use in solution-processed bulk heterojunction small molecule solar cells is reported. Optical and electrochemical data show that increasing oligothiophene $\pi$-bridge length leads to a decrease of the optical band gap due to a parallel increase of the highest occupied molecular orbital (HOMO) level. Furthermore, subtle modifications of a molecular $\pi$-bridge length strongly affect the thermal behavior, solubility, crystallization, film morphology and charge carrier mobility, which in turn significantly change the device performance. Although the moderately increasing oligothiophene $\pi$-bridge length uplifts the HOMO level, it nevertheless induces an increase of the efficiency of the resulting solar cells due to a simultaneous improvement of the short circuit current $\left(J_{\text {sc }}\right)$ and fill factor (FF). The study demonstrates that such an approach can represent an interesting tool for the effective modulation of the photovoltaic properties of the organic solar cells (OSCs) at a moderate cost.
\end{abstract}

\section{Introduction}

During the last decade, bulk heterojunction (BHJ) organic solar cells (OSCs) utilizing conjugated polymers or small molecules have attracted attention due to the low fabrication costs achievable via solution-processing methods. ${ }^{1-6}$ In particular,

${ }^{a}$ Institute of Materials for Electronics and Energy Technology (I-MEET), Friedrich-Alexander-University Erlangen-Nuremberg, Martensstraße 7, 91058 Erlangen, Germany. E-mail: Min.Jie@ww.uni-erlangen.de

${ }^{b}$ Enikolopov Institute of Synthetic Polymeric Materials of the Russian Academy of Sciences, Profsoyuznaya st. 70, Moscow 117393, Russia

'Scientific and Research Centre Kurchatov Institute, 1 Kurchatov square, Moscow, 123182, Russia

${ }^{d}$ Moscow Institute of Physics and Technology, 4 Institutsky line, Dolgoprudny, Moscow region, 141700, Russia

${ }^{e}$ Nesmeyanov Institute of Organoelement Compounds, Russian Academy of Sciences, Vavilova St. 28, Moscow, 119991, Russia

${ }^{{ }^{H} H e r a e u s}$ Precious Metals GmbH \& Co. KG, Conductive Polymers Division (Clevios), Chempark Leverkusen Build. B202, D-51368 Leverkusen, Germany

${ }^{g}$ Chemistry Department, Moscow State University, Leninskie Gory 1-3, Moscow 119991, Russia

${ }^{h}$ Bavarian Center for Applied Energy Research (ZAE Bayern), Haberstraße 2a, 91058 Erlangen, Germany

$\dagger$ Electronic supplementary information (ESI) available: Material synthesis, ${ }^{1} \mathrm{H}$ and ${ }^{13} \mathrm{C}$ NMR spectra of monomers, TGA and DSC plots, CV curves, XRD data and hole mobilities measurements of pristine and blended films. See DOI: $10.1039 / \mathrm{c} 4$ ta01933d intensive research on small molecule OSCs has been carried out resulting in a remarkable improvement of the photovoltaic performance by judicious molecular design, morphology control and device optimization. ${ }^{4-7}$ They are emerging as promising substitutes for conjugated polymers owing to the advantages of simple synthesis, definite molecular structure and weight, high purity, and reproducible photovoltaic performance. ${ }^{8}$ The current research is focused on obtaining high molecular physical and photovoltaic properties by the design and synthesis of novel push-pull molecular systems built by connecting various electron donating (donor) and electron capturing (acceptor) moieties through a $\pi$-conjugating spacer $(D-\pi-A)$. Such an approach can be used to lower the optical band gap to broaden molecular optical absorption and assist the formation of favorable morphologies for high photovoltaic performance. ${ }^{9}$ It is also apparent that desirable highest occupied molecular orbital (HOMO) and lowest unoccupied molecular orbital (LUMO) levels can be obtained by coupling a wide variety of donor and acceptor units. ${ }^{10}$ A large number of D-A small molecules, such as linear molecules, ${ }^{\mathbf{4 , 5 , 8 , 1 1 , 1 3 - 1 5}}$ star-shaped molecules ${ }^{12,16-19}$ and other organic dyes, ${ }^{20}$ have been extensively studied and exhibited considerable molecular photovoltaic properties. More recently, using this class of compounds, the best power conversion efficiency (PCE) of OSCs reached $8 \%$ for single junction solar cells, ${ }^{4,14}$ and $10 \%$ for double-junction 
tandem OSCs,${ }^{\mathbf{1 4}}$ endowing organic small molecules with a great application potential for the generation of low cost solar cells.

However, compared to $\pi$-conjugated polymers, relatively short conjugated backbone of $\mathrm{D}-\mathrm{A}$ small molecules reduces the tendency for the formation of interpenetrating networks and mixed morphologies when blended with fullerene derivatives. $^{21,22}$ Furthermore, the limited conjugation length makes charge transport in these materials primarily intermolecular with a negligible intramolecular component, which increases charge recombination in OSCs causing low photocurrent and low fill factor (FF). ${ }^{9}$ Overcoming these obstacles requires to enhance intramolecular $\pi-\pi$ stacking interactions and facilitate charge transport and collection in D-A small molecule OSCs, as well as to further increase the PCE. A promising approach is to incorporate two dimensional (2-D) or star-shaped conjugated structures into D-A conjugated systems..$^{\mathbf{4 1 4 , 1 7 , 2 3}}$ These structures can enhance intramolecular $\pi-\pi$ interactions extending the conjugated surface of small molecules. Substantial progress has recently been made in small molecule OSCs by introducing alkylthienyl-co-vinyl conjugated side chains in an oligothiophene for the formation of a 2-D conjugated structure, achieving a PCE of $c a .4 \%{ }^{23 a}$ Remarkably, the PCEs surpassing $8 \%$ have also been reported more recently by employing alkylthienyl and alkylbithienyl substituted benzodithiophene (BDT) moieties in the core of $\mathrm{A}-\pi-\mathrm{D}-\pi-\mathrm{A}$ type linear molecules. ${ }^{4}$ In addition, moderate increase of the molecular size and $\pi$-bridge length within structurally well-defined D-A small molecules is another smart strategy of facilitating charge transport and improving molecular properties by the extension of the conjugated backbone and corresponding modification of the electronic properties. ${ }^{24,25}$ For instance, Bazan et al. have described the effects and merits of increasing molecular size within structurally welldefined D-A linear molecules on relevant physical and photovoltaic properties. ${ }^{24}$ In addition, Wang et al. showed that the absorption maximum red-shifts, the optical bandgap decreases, photovoltaic properties gradually improve for 2,7-carbazole based D-A conjugated linear molecules with different number of the terminal thiophene units from one, two to three. ${ }^{25}$ However, the research devoted to the development of D-A star-shaped molecules with different molecular size as well as varying $\pi$ bridge length is inadequate, especially when compared to the amount of research devoted to linear molecules. ${ }^{\mathbf{2 4 2 5}}$ Therefore, the effect of $\pi$-bridge length in star-shaped molecules can possibly provide a subtle way of controlling film morphology and device performance, providing more detailed insights into their structure-property relationships.

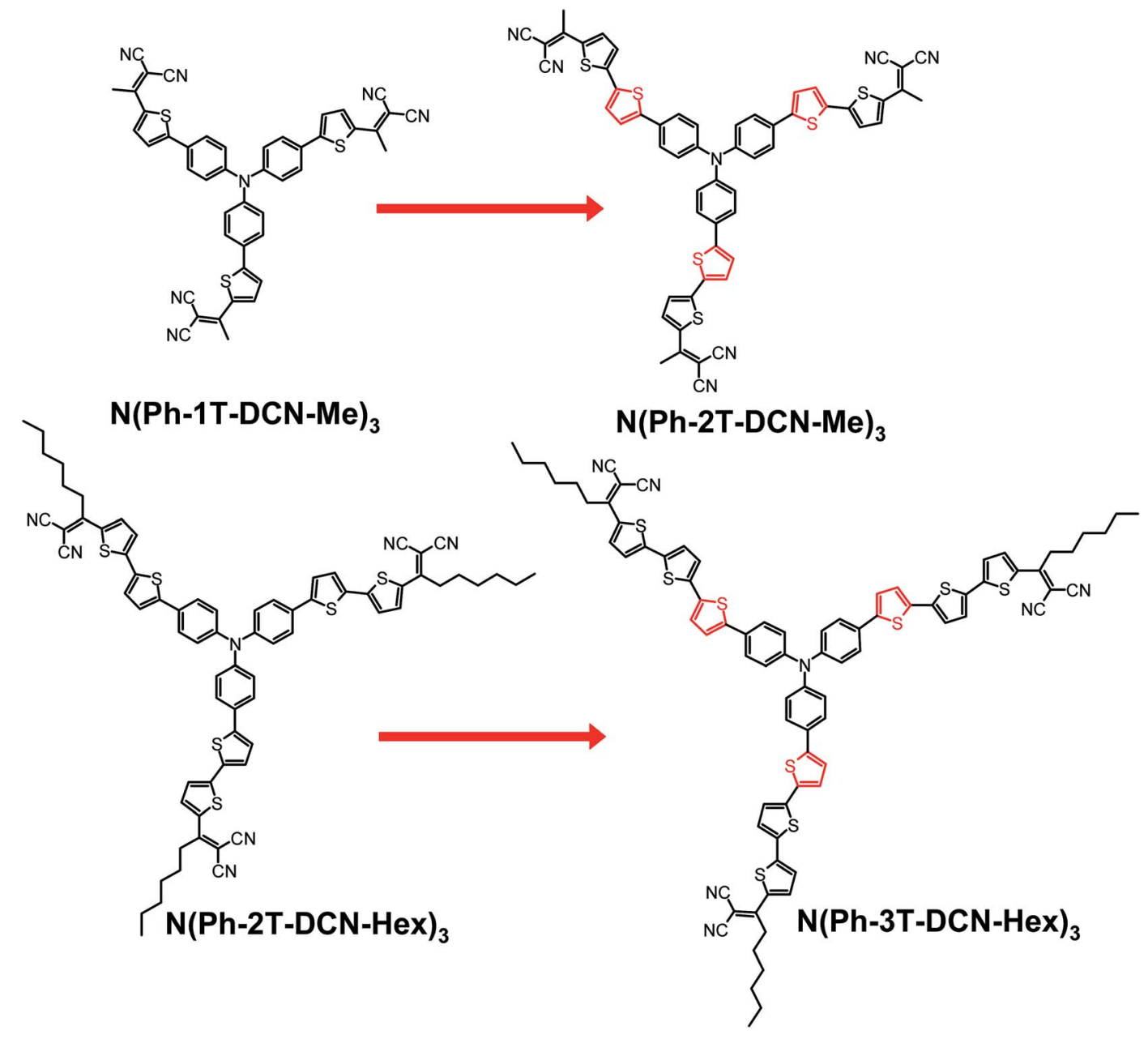

Fig. 1 Molecular structures of the investigated TPA-based star-shaped molecules. 
In recent years, triphenylamine (TPA) based star-shaped molecules have been developed as an interesting class of semiconducting materials. They were used in OSCs because of their good solubility and high hole mobility. ${ }^{26,27}$ Roncali and coworkers firstly reported a series of TPA-based star-shaped molecules with a D- $\pi-\mathrm{A}$ architecture. ${ }^{28-30}$ Increasing the number of electron withdrawing groups in this series of compounds caused a deepening of the HOMO energy level and a decrease in the optical band gap with corresponding increase in open circuit voltage $\left(V_{\mathrm{oc}}\right)$ and short circuit current $\left(J_{\mathrm{sc}}\right)$. Hereafter, Li et al. introduced vinylene bridges between TPA and oligothiophene fragments to improve the molecular effective conjugated bridge length and photovoltaic properties. ${ }^{31}$ Recently, modifying alkyl side chains' position and length to reduce steric hindrance and improve the strength of molecular $\pi$-conjugated bridges, our group reported a series of TPA-based star-shaped molecules, ${ }^{\mathbf{1 6}, 17}$ including $\mathbf{N}(\mathbf{P h}-2 \mathrm{~T}-\mathbf{D C N}-\mathbf{M e})_{3}$ and N(Ph-2T-DCN-Hex) $)_{3}$ (see Fig. 1 for molecular structures). The resulting OSC based on N(Ph-2T-DCN-Me $)_{3}$ provided a PCE of $4.76 \%$, which is the highest reported value for the OSCs based on star-shaped molecules. However, the influence of molecular size and/or $\pi$-bridge length within structurally well-defined TPA-based molecules on the properties relevant to OSCs, was not systematically studied. Obviously, it would be interesting to explore the physical and photovoltaic properties of some D- $\pi-\mathrm{A}$ conjugated star-shaped small molecules with various molecular sizes by introducing oligothiophene $\pi$-bridges of different lengths into each branch of the molecule. We envisioned that extending conjugated oligothiophene $\pi$-bridges into TPA-based star-shaped molecules could substantially enhance absorption, alleviate the film morphology and improve charge carrier mobility, which are indispensable for high performance photovoltaic devices. Thus, two new TPA-based star-shaped molecules $\mathbf{N}(\mathbf{P h}-\mathbf{1 T}-\mathbf{D C N}-\mathbf{M e})_{3}$ and $\mathbf{N}(\mathbf{P h}-\mathbf{3 T}-\mathbf{D C N}-\mathbf{H e x})_{3}$ were designed and synthesized with thiophene (1T) and terthiophene (3T) as $\pi$-conjugated bridges, as shown in Fig. 1 . Combined with $\mathbf{N}(\mathbf{P h}-2 \mathrm{~T}-\mathrm{DCN}-\mathbf{M e})_{3}$ and $\mathbf{N}(\mathbf{P h}-2 \mathrm{~T}-\mathrm{DCN}-\mathbf{H e x})_{\mathbf{3}}$ with bithiophene (2T) as $\pi$-conjugated bridges, we systematically investigated the influence of oligothiophene $\pi$-bridges of varying conjugation length on relevant physical and photovoltaic properties of starshaped small molecules with a D- $\pi-\mathrm{A}$ architecture. It should be noted that $\mathbf{N}(\mathbf{P h}-2 \mathrm{~T}-\mathbf{D C N}-\mathbf{M e})_{3}$ and $\mathbf{N}(\mathbf{P h}-\mathbf{2 T}-\mathbf{D C N}-\mathbf{H e x})_{3}$ are simultaneously introduced to exclude the influence of alkyl chain groups in the investigation. The detailed characterization of their thermal, optical and electrochemical properties, solubility, film structure and morphology, charge transport, and photovoltaic performance are presented.

\section{Results and discussion}

\subsection{Synthesis and characterization of the star-shaped molecules}

Preparation of TPA-based star-shaped molecules (Fig. 1) is outlined in Scheme 1 . Synthesis of $\mathbf{N}(\mathbf{P h}-\mathbf{2 T - D C N}-\mathbf{M e})_{3}$ and $\mathbf{N}(\mathbf{P h}-2 \mathrm{~T}-\mathrm{DCN}-\mathrm{Hex})_{\mathbf{3}}$ were described in detail previously. ${ }^{\mathbf{1 6}}$ The two new TPA-based molecules, N(Ph-1T-DCN-Me $)_{3}$ and N(Ph3T-DCN-Hex $)_{3}$ were prepared similar to the previously developed synthetic approach based on preparation of the star-shaped triketones followed by a Knövenagel condensation with malononitrile under a microwave irradiation. ${ }^{16,17}$ Synthesis of $\mathbf{N}(\mathbf{P h}-1 \mathrm{~T}-\mathrm{DCN}-\mathrm{Me})_{3}$ and $\mathbf{N}(\mathbf{P h}-\mathbf{3 T}-\mathbf{D C N}-\mathbf{H e x})_{3}$ consists of six consecutive reaction stages (see Scheme 1, and experimental part in ESI $\dagger$ ). First, the preparation of ketone precursors (2a and 2d) by the acylation of magnesium derivatives of thienyl (1a) and terthienyl (1d) bromides with corresponding alkanoyl chlorides, using lithium manganese chloride as a catalyst, was carried out. Second, the protected ketones (3a and $\mathbf{3 d}$ ) were prepared by reactions of $\mathbf{2 a}$ and $\mathbf{2 d}$ with 2,2-dimethyl-1,3-propanediol or ethylene glycol, respectively, at the presence of $p$-toluenesulfuric acid. It is interesting to note that the protection of 2a with ethylene glycol was found to be unsuccessful in this case because of the extremely high instability of 1,3-dioxolane (DOX) groups during the isolation and purification procedures. This problem was successfully overcome by the use of more stable 5,5-dimethyl-1,3-dioxane (DMOX) protective groups. The third stage included the synthesis of pinacol boronic esters of the corresponding protected ketones (4a and 4d) via the reaction of lithium derivatives of compounds $3 \mathbf{a}$ and 3d with 2-isopropoxy-4,4,5,5-tetramethyl-1,3,2-dioxaborolane (IPTMDOB). On the fourth stage the synthesis of star-shaped compounds $\mathbf{5 a}$ and $\mathbf{5 d}$ was carried out via Suzuki cross-coupling between tris(4-bromophenyl)amine and compounds $4 \mathbf{b}$ or $4 \mathbf{d}$, respectively. In the next stage, deprotection of $\mathbf{5 a}$ and $\mathbf{5 d}$ by treatment of their THF solutions with hydrochloric acid gave the poorly soluble star-shaped ketones $\mathbf{6}$ a and $\mathbf{6 d}$ in high yields. Finally, N(Ph-1T-DCN-Me $)_{3}$ and N(Ph-3T-DCN-Hex $)_{3}$ were obtained by Knövenagel condensation reaction of compounds

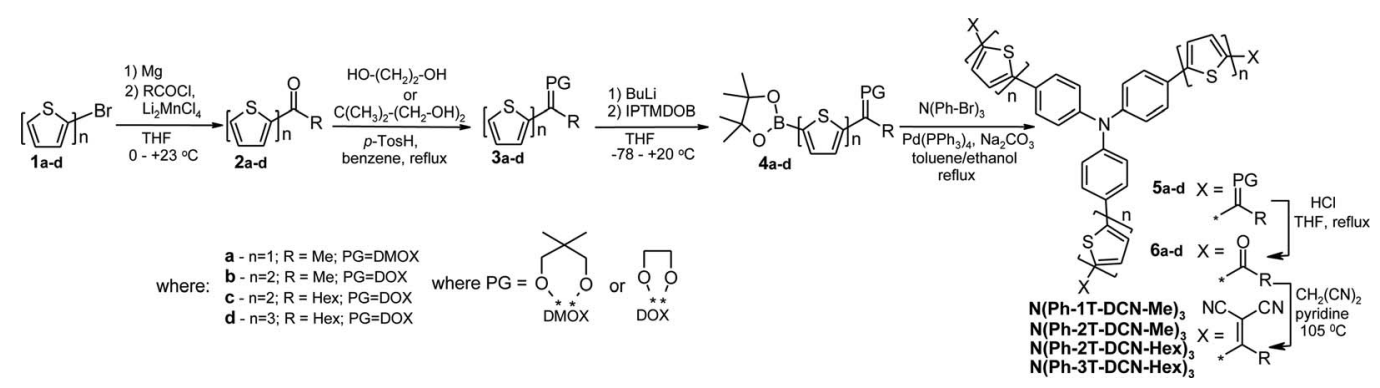

Scheme 1 Synthesis of star-shaped molecules. 
6a and $\mathbf{6 d}$ with the excess of malononitrile in pyridine using a microwave heating.

GPC, ${ }^{1} \mathrm{H}$ - and ${ }^{13} \mathrm{C}$-NMR spectroscopy, elemental analysis, high resolution mass-spectroscopy and MALDI-TOF studies were used to characterize the molecular structure and purity of these molecules (see ESI, Fig. S1-S23 $\dagger$ ). N(Ph-1T-DCN-Me) $)_{3}$, N(Ph-2T-DCN-Me $)_{3}, \quad$ N(Ph-2T-DCN-Hex $)_{3}$, and N(Ph-3T-DCNHex $)_{3}$ were readily soluble in common organic solvents such as THF, chloroform, dichloromethane, etc. Since N(Ph-2T-DCNMe) $)_{3}$ demonstrates somewhat lower solubility at room temperature, $\mathbf{N}(\mathbf{P h}-\mathbf{3 T} \text {-DCN-Hex })_{3}$ based on terthiophene bridges and hexyl terminal chains was introduced for the sake of comparison with the bithiophene bridge-based N(Ph-2T-DCN-Hex $)_{3}$, taking into account the influence of alkyl terminal chains.

\subsection{Thermal properties and solubility}

Thermal properties of the four TPA-based molecules were studied by thermogravimetric analysis (TGA) and differential scanning calorimetry (DSC). Fig. S24-S27 (see ESI $\dagger$ ) show the results of TGA of the studied compounds in the air and nitrogen flow correspondingly. One can see that in the inert atmosphere the compounds possess very high thermostability (Fig. S24 $\dagger$ ), starting to decompose only above $370{ }^{\circ} \mathrm{C}$ (see the temperature of $5 \%$ weight loss $\Delta T_{5 \%}, \mathrm{~N}_{2}$ in Table 1 ). The comparison of the loss of weight at very high temperatures indicates unambiguously that this is due to decomposition of the aliphatic tails together with the dicyano groups. The lowest weight loss was observed for N(Ph-2T-DCN-Me $)_{3}$ (19\%). It is a bit higher for N(Ph-1T-DCN$\mathbf{M e})_{3}(21 \%)$ due to the increased proportion of methyl ends $v s$. oligothiophene fragments (2T in the former case and $1 \mathrm{~T}$ in the latter). For compounds with hexyl tails the weight loss was 35$40 \%$, which is also in good agreement with the molecular composition (weight fraction of the aliphatic tails together with the dicyano groups). In the air flow all the compounds start losing weight at $300{ }^{\circ} \mathrm{C}$, totally decomposing without leftover at $550{ }^{\circ} \mathrm{C}$, as shown in Fig. S25. $\dagger$

First heating DSC scans of N(Ph-1T-DCN-Me) ${ }_{3}$ (Fig. S25 $\dagger$ ) are characterized by two endothermal peaks at $160{ }^{\circ} \mathrm{C}\left(\Delta H_{1}=4.7 \mathrm{~J}\right.$ $\left.\mathrm{g}^{-1}\right)$ and $276{ }^{\circ} \mathrm{C}\left(\Delta H_{2}=60.7 \mathrm{~J} \mathrm{~g}^{-1}\right)$. Analysis of the temperature behavior of N(Ph-1T-DCN-Me $)_{3}$ revealed that the first transition is crystal-crystal transformation (see Fig. S30), while the second one corresponds to the sample isotropization. It should be underlined that after annealing at $260{ }^{\circ} \mathrm{C}$ and subsequent cooling, high temperature crystal modification appeared to be stable down to room temperature: compare curves 2 and 3 on
Fig. S30b. $\dagger$ Parameters of its crystal lattice will be presented later on. Other materials studied are characterized by glass transition only (see Fig. S27†). Its temperature decreases with increasing the length of aliphatic tails, as shown in Table 1. Moreover, an increase of the length of oligothiophene bridge leads to higher glass transition temperature of the material due to increased rigidity of the branches of the molecule.

Solubilities of the four compounds were determined in $o$-dichlorobenzene (ODCB) at room temperature by a reported $\operatorname{method}^{32}$ and are listed in Table 1 . The four compounds have a solubility sequence of N(Ph-2T-DCN-Me $)_{3}<$ N(Ph-1T-DCN-Me $)_{3}$ $<\mathbf{N}(\text { Ph-3T-DCN-Hex })_{3}<\mathbf{N}(\mathbf{P h}-2 T-D C N-H e x)_{3}$, opposite to the sequence of glass transition temperatures. N(Ph-2T-DCN-Me $)_{3}$ has the lowest solubility $\left(<3 \mathrm{mg} \mathrm{mL}^{-1}\right)$ because the short methyl chains as solubilizing groups result in strong $\pi-\pi$ interactions. In contrast, $\mathbf{N}(\mathbf{P h}-\mathbf{2 T} \text {-DCN-Hex })_{3}$ has the highest solubility (20 $\mathrm{mg} \mathrm{mL} \mathrm{m}^{-1}$ in ODCB) because of weak $\pi-\pi$ interactions due to the effect of long hexyl chains manifesting itself in twisted conformation between oligothiophene bridges and acceptor units. In addition, N(Ph-1T-DCN-Me $)_{3}$ has higher solubility than N(Ph2T-DCN-Me $)_{3}\left(6 \mathrm{mg} \mathrm{mL}^{-1}\right.$ vs. $\left.<3 \mathrm{mg} \mathrm{mL}^{-1}\right)$, which is attributed to the reduced oligothiophene bridges. The solubility of N(Ph3T-DCN-Hex $)_{3}$ underlines that simply extending the oligothiophene bridges leads to a relatively lower solubility and strong $\pi-$ $\pi$ interactions. Saturated alkyl chains (e.g. hexyl chains) often cause the conjugated backbone to twist, which reduces the effective conjugation length and consequently increases the optical band gap. Therefore, a moderate extension of the oligothiophene $\pi$-bridge can possibly improve the effective conjugation length and optical absorption as discussed below.

\subsection{Photophysical and electrochemical properties}

The UV-vis absorption spectra of the small molecules in dilute ODCB solutions and films are shown in Fig. 2. Samples used for the measurement of film absorption spectra were prepared by doctor-blading from ODCB solutions. The corresponding optical data are summarized in Table 2. In ODCB solution, N(Ph-1T-DCN-Me $)_{3}$ exhibits two distinct absorption peaks, the UV absorption peak at $363 \mathrm{~nm}$ in the shorter wavelength region corresponds to the $\pi-\pi^{*}$ transition, and the visible adsorption peak at $495 \mathrm{~nm}$ is attributed to the intramolecular chargetransfer (ICT) transition between the TPA-thiophene donor unit and the dicyanovinyl (DCN) acceptor unit. With an increasing $\pi$ conjugated bridge length of each branch the absorption peaks of N(Ph-2T-DCN-Me $)_{3} / \mathbf{N}(\mathbf{P h}-2 \mathrm{~T}-\mathrm{DCN}-\mathrm{Hex})_{3}$ and N(Ph-3T-DCN-

Table 1 Thermal properties and solubility of four TPA-based molecules

\begin{tabular}{lcllr}
\hline Compound & $T_{\mathrm{g}}{ }^{a}\left({ }^{\circ} \mathrm{C}\right)$ & $\Delta C_{\mathrm{p}}{ }^{a}\left(\mathrm{~J} \mathrm{~g}^{-1} \mathrm{~K}^{-1}\right)$ & $\Delta T_{5 \%}, \mathrm{~N}_{2},{ }^{\circ} \mathrm{C}$ & Solubility $^{b}\left(\mathrm{mg} \mathrm{mL}^{-1}\right)$ \\
\hline $\mathbf{N}(\text { Ph-1T-DCN-Me })_{3}{ }^{c}$ & 128 & 0.27 & 395 & 6 \\
$\mathbf{N}(\text { Ph-2T-DCN-Me })_{3}$ & 159 & 0.21 & 453 & $<3$ \\
N(Ph-2T-DCN-Hex) & 64 & 0.25 & 401 & 20 \\
N(Ph-3T-DCN-Hex $)_{3}$ & 72 & 0.29 & 388 & 12
\end{tabular}

\footnotetext{
${ }^{a}$ Parameters of glass transition in the compounds studied by DSC method. ${ }^{b}$ In ODCB at room temperature, determined by the method in ref. 32 .

${ }^{c}$ Second heating of the once melted material.
} 

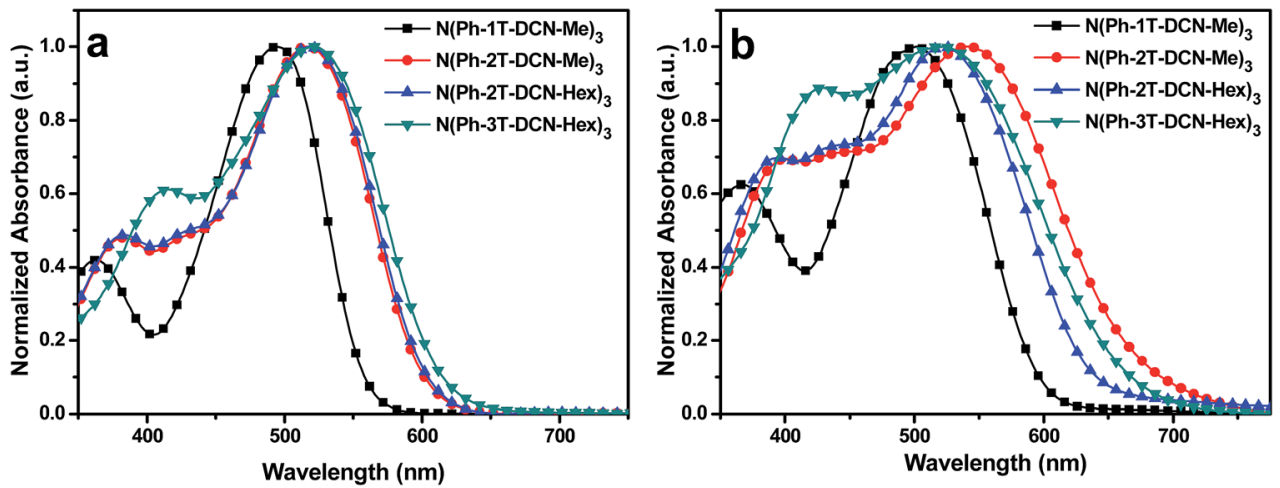

Fig. 2 UV-vis absorption spectra of $\mathrm{N}(\mathrm{Ph}-1 \mathrm{~T}-\mathrm{DCN}-\mathrm{Me})_{3}, \mathrm{~N}(\mathrm{Ph}-2 \mathrm{~T}-\mathrm{DCN}-\mathrm{Me})_{3}, \mathrm{~N}(\mathrm{Ph}-2 \mathrm{~T}-\mathrm{DCN}-\mathrm{Hex})_{3}$, and $\mathrm{N}(\mathrm{Ph}-3 \mathrm{~T}-\mathrm{DCN}-\mathrm{Hex})_{3}$ in $\mathrm{ODCB}$ solution (a) and in the film (b).

Table 2 Optical and electrochemical properties of the TPA-based molecules

\begin{tabular}{|c|c|c|c|c|c|c|c|}
\hline Compounds & \multicolumn{4}{|c|}{ UV-vis absorption spectra } & \multicolumn{3}{|l|}{ Cyclic voltammetry } \\
\hline $\mathrm{N}(\mathrm{Ph}-1 \mathrm{~T}-\mathrm{DCN}-\mathrm{Me})_{3}$ & 495 & 502 & 605 & 2.05 & $1.20 /-5.60$ & $-0.94 /-3.46$ & 2.14 \\
\hline $\mathbf{N}(\mathbf{P h}-2 \mathrm{~T}-\mathrm{DCN}-\mathrm{Me})_{3}{ }^{d}$ & 517 & 541 & 711 & 1.74 & $0.92 /-5.32$ & $-0.99 /-3.41$ & 1.91 \\
\hline
\end{tabular}

Hex) $)_{3}$ solution are red-shifted significantly to $517 / 517$ and 522 $\mathrm{nm}$, respectively, despite of the tendencies of absorption maxima $\left(\lambda_{\max }\right)$ and absorption onset $\left(\lambda_{\text {onset }}\right)$ to the saturation. Probably, the longer oligothiophene $\pi$-bridges linkage between TPA and DCN eliminate torsional interactions and increase the intensity of the ICT transition. In addition, the shorter wavelength region peaks redshift from $363 \mathrm{~nm}$ to $382 / 382 \mathrm{~nm}$ and $416 \mathrm{~nm}$ for $\mathbf{N}(\mathbf{P h}-2 \mathrm{~T}-\mathrm{DCN}-\mathrm{Me})_{3}, \mathbf{N}(\mathbf{P h}-2 \mathrm{~T}-\mathrm{DCN}-\mathbf{M e})_{3} / \mathbf{N}(\mathbf{P h}-2 \mathrm{~T}-$ DCN-Hex $)_{3}$ and $\mathbf{N}(\mathbf{P h}-3 \mathbf{T}-\mathbf{D C N}-\mathbf{H e x})_{3}$, respectively, which is attributed to the stronger localized $\pi-\pi *$ transition arising from the longer oligothiophene $\pi$-bridge lengths. The difference in position and intensity of the absorption spectra are mainly due to the different structures of the $\pi$-bridges in the molecules. Comparative analysis of solution and films' photophysical properties revealed that absorption spectra of N(Ph-1T-DCN$\mathbf{M e})_{3}, \quad \mathbf{N}(\mathbf{P h}-2 \mathrm{~T}-\mathrm{DCN}-\mathrm{Me})_{3}$, and $\mathbf{N}(\mathbf{P h}-2 \mathrm{~T}-\mathrm{DCN}-\mathrm{Hex})_{3}$ become broader and their absorption peaks are significantly red-shifted. However, the absorption peak of N(Ph-3T-DCN-Hex $)_{3}$ is negligibly shifted between solution and film due to the weak aggregation and intermolecular interactions of the molecules in the solid state. ${ }^{33}$ Among these star-shaped molecules, $\lambda_{\max }$ and $\lambda_{\text {onset }}$ of N(Ph-2T-DCN-Me $)_{3}$ are most significantly red-shifted by $23 \mathrm{~nm}$ and $111 \mathrm{~nm}$, respectively, indicating the efficient $\pi$ stacking and strong intermolecular interactions in the film. ${ }^{16} \mathrm{~A}$ reduced solid state band gap of $1.74 \mathrm{eV}$ is achieved for $\mathbf{N}(\mathbf{P h}-\mathbf{2 T}$ -
DCN-Me $)_{3}$ based on bithiophene bridges, $0.31 \mathrm{eV}$ lower than that for N(Ph-1T-DCN-Me $)_{3}$ based on a simple thiophene bridge. This may be attributed to the increased effective conjugation length and improved electronic communication between TPA and DCN units. In addition, $\lambda_{\text {onset }}$ of $\mathbf{N}(\mathbf{P h}-\mathbf{2 T - D C N - H e x})_{3}$ is significantly blue-shifted by $54 \mathrm{~nm}$ as compared to $\mathbf{N}(\mathbf{P h}-2 \mathbf{T}$ DCN-Me $)_{3}$, corresponding to a minor difference in planarity caused by the steric hindrance of the terminal chains. Finally, compared to the other three compounds, the absorption intensity of $\mathbf{N}(\mathbf{P h}-\mathbf{3 T}-\mathbf{D C N}-\mathbf{H e x})_{\mathbf{3}}$ in the shorter wavelength region is higher. This suggests that longer oligothiophene $\pi$ bridge effectively releases the distortion induced by the long alkyl terminal chains.

The electrochemical properties of the four TPA-based starshaped molecules and their HOMO and LUMO energy levels were examined by cyclic voltammetry (CV) (see Table 2 and Fig. S28 and S29 in the ESI†). From the value of the onset reduction potentials $\left(\varphi_{\text {red }}\right)$ and the onset oxidation potentials $\left(\varphi_{\text {ox }}\right)$, the LUMO and HOMO energy levels of these molecules were calculated as shown in Table 2, according to the equations of LUMO $=-e\left(\varphi_{\text {red }}+4.40\right)(\mathrm{eV})$ and HOMO $=-e\left(\varphi_{\mathrm{ox}}+4.40\right)$ $(\mathrm{eV}){ }^{34}$ The LUMO energy levels were determined to be $-3.46 \mathrm{eV}$ for N(Ph-1T-DCN-Me $)_{3},-3.41 \mathrm{eV}$ for N(Ph-2T-DCN-Me $)_{3},-3.41$ $\mathrm{eV}$ for N(Ph-2T-DCN-Hex $)_{3}$, and $-3.40 \mathrm{eV}$ for N(Ph-3T-DCNHex $)_{3}$ by the above-mentioned equation, revealed that the 
measured LUMO energy levels of these four molecules are very close. Therefore, the incorporation of various oligothiophene $\pi$ bridges has little effect on their LUMO level differences. However, it is interesting to note that the HOMO energy levels are significantly different due to the effect of $\pi$-conjugated bridges with various electron donating characters. ${ }^{35}$ Owing to the strong electron-donating terthiophene units as $\pi$-bridges, which usually increases the HOMO energy level, N(Ph-3T-DCNHex $)_{3}$ exhibits a high HOMO energy level of $-5.26 \mathrm{eV}$. And it is $0.34 \mathrm{eV}$ higher than that of N(Ph-1T-DCN-Me $)_{3}(-5.60 \mathrm{eV})$ because of its relatively weak electron-donating thiophene bridges. In addition, the HOMO energy levels of N(Ph-2T-DCN$\mathbf{M e})_{3}$ and $\mathbf{N}(\mathbf{P h}-2 \mathrm{~T}-\mathbf{D C N}-\mathbf{H e x})_{3}$ are in between the HOMO energy levels of N(Ph-1T-DCN-Me $)_{3}$ and N(Ph-3T-DCN-Hex $)_{3}$, as shown in Table 2. Earlier, BHJ OSCs based on N(Ph-2T-DCN-Me $)_{3}$ and N(Ph-2T-DCN-Hex $)_{3}$ with [6,6]-phenyl-C71-butyric acid methyl ester $\left(\mathrm{PC}_{71} \mathrm{BM}\right)$ acceptors exhibited high $V_{\mathrm{oc}}$ of $0.98 \mathrm{~V}$. Therefore, a comparable high $V_{\text {oc }}$ is expected for N(Ph-1T-DCN-Me $)_{3}$ and a slightly low $V_{\mathrm{oc}}$ is expected for N(Ph-3T-DCN-Hex $)_{3}$, because $V_{\mathrm{oc}}$ is mainly determined by the difference between the HOMO of the donor and the LUMO of the acceptor. ${ }^{35}$

\subsection{X-ray diffraction}

Here, we further investigate the effects of oligothiophene $\pi$ bridge length on the packing of the molecules in solid state by XRD analysis. At room temperature N(Ph-1T-DCN-Me $)_{3}$ is highly crystalline, as is shown by DSC (Fig. S26†) and X-ray scattering (Fig. S30†) studies. Annealing at $260^{\circ} \mathrm{C}$ allowed to get a stable crystal phase of triclinic symmetry with parameters $a=11.47 \AA$, $b=18.17 \AA, c=18.30 \AA, \alpha=98.3^{\circ}, \beta=52.2^{\circ}, \gamma=130.7^{\circ}$ (see Table S1 and Fig. 3). Such mutual arrangement provides the optimum $\pi-\pi$ interaction between the neighbouring molecules. Calculated density of the crystalline phase appeared to be $\rho_{\text {calc }}=$ $1.227 \mathrm{~g} \mathrm{~cm}^{-3}$ which is higher than experimentally observed value of the density $\rho_{\exp } \sim 0.98 \mathrm{~g} \mathrm{~cm}^{-3}$. However, such

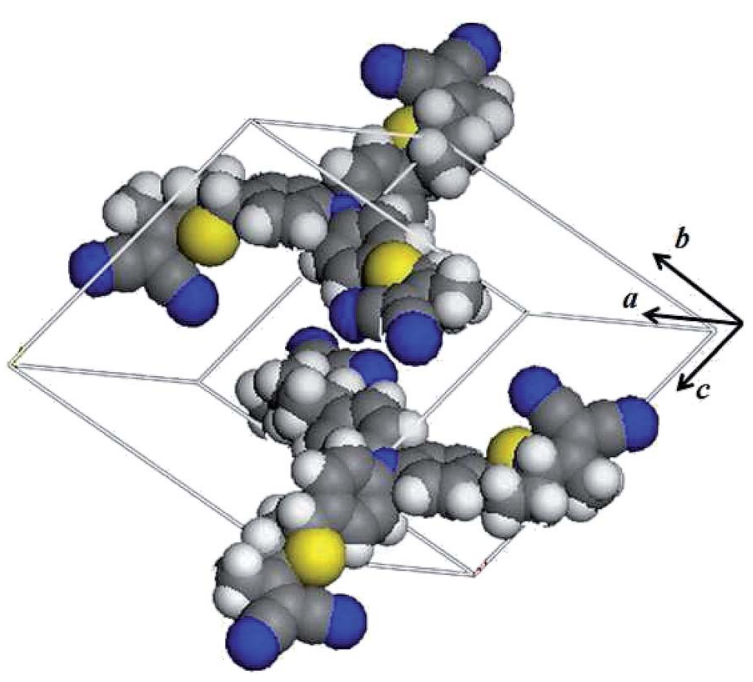

Fig. 3 Packing of the molecules of compound N(Ph-1T-DCN-Me $)_{3}$ in the triclinic crystal lattice with parameters $a=11.47 \AA, b=18.17 \AA, c=$ $18.30 \AA, \alpha=98.3^{\circ}, \beta=52.2^{\circ}, \gamma=130.7^{\circ}$. discrepancy is reasonable as real crystals can possess a number of defects upsetting the equilibrium arrangement of the molecules. Moreover, the samples can also contain the regions of the quenched amorphous phase having substantially lower density. Melting the $\mathbf{N}(\mathbf{P h}-\mathbf{1 T}-\mathbf{D C N}-\mathbf{M e})_{3}$ compound leads to its irreversible transformation to the amorphous state - crystalline phase does not recover on slow cooling after heating to $290{ }^{\circ} \mathrm{C}$. Only glass transition is observed at $128{ }^{\circ} \mathrm{C}$ (see Table 1).

Wide-angle measurements of X-ray scattering revealed that all samples but $\mathbf{N}(\mathbf{P h}-\mathbf{1 T}-\mathbf{D C N}-\mathbf{M e})_{3}$ do not possess crystalline order. At room temperature, a wide halo was observed on the corresponding scattering curves (Fig. S31†). However, comparatively narrow reflection on curve 4 corresponding to $d$-spacing of $5.55 \AA$ should be noted. This is ascribed to the remnants of the ordering of crystal-solvates. However, it should be noted that crystalline modification of $\mathbf{N}(\mathbf{P h}-\mathbf{2 T}-\mathbf{D C N}-\mathbf{M e})_{3}$ compound can be obtained by the crystallization from solution. It has a melting temperature of $T_{\mathrm{m}}=248{ }^{\circ} \mathrm{C}\left(\Delta H=60.7 \mathrm{~J} \mathrm{~g}^{-1}\right)$. Temperature behaviour of such samples is rather similar to that of $\mathbf{N}(\mathbf{P h}-\mathbf{1 T}-\mathbf{D C N}-\mathbf{M e})_{3}$ compound. In the melted material, crystal phase does not reappear even after slow cooling with $2{ }^{\circ} \mathrm{C}$ $\min ^{-1}$ cooling rate.

In contrast to the crystalline $\mathbf{N}(\mathbf{P h}-\mathbf{1 T}-\mathbf{D C N}-\mathbf{M e})_{3}$, and to the amorphous N(Ph-2T-DCN-Me $)_{3}$ and N(Ph-2T-DCN-Hex $)_{3}$, which do not reveal any reflections in small-angle X-ray scattering (SAXS) patterns (Fig. S32, $\uparrow$ curve 1), N(Ph-3T-DCN-Hex) $)_{3}$ at room temperature is characterized by a set of three reflections with the ratios of corresponding $d$-spacings $d_{1}{ }^{2}: d_{2}{ }^{2}: d_{3}{ }^{2}=1: 3: 4$ (Fig. S32, $\dagger$ curve 2). They can be indexed by 2D hexagonal columnar phase with cylinder diameter $D=23.7 \AA$. Moreover, wide halo is observed at $s=0.16 \AA^{-1}$. Its origin relates to the Fourier transform of single cylinder of columnar mesophase. With the temperature increasing, mesophase reflections of compound N(Ph-3T-DCN-Hex $)_{3}$ shift to small angles, diameter of the columns increased to $23.9 \AA$ at $120{ }^{\circ} \mathrm{C}$ (Fig. S32, $\dagger$ curve 3 ). Such a change corresponds to thermal expansion coefficient $\beta=$ $1.3 \times 10^{-4} \mathrm{~K}^{-1}$. As the diameter of the molecule envelope is 30.6 $\AA$, substantial correlation between the relative positions of the molecules in neighboring molecules should be suggested (Fig. 4). There is no order in the packing of the molecules along the column axis (because of the absence of diffraction maxima on wide-angle X-ray scattering patterns), as well as no ordering between the neighboring columns, summarizing the pattern of molecular packing is irregular in each transverse section due to the steric necessity of mutual packing of long $\pi$-conjugated bridges, while column centers form 2D hexagonal lattice. Appearing steric limitations lead to the azimuthal irregularities in stacking of the molecules along the column, as every molecule should adjust its position not only with its top and bottom neighbors inside the cylinder, but with its side neighbors as well. An interesting feature of the columnar mesophase in compound $\mathbf{N}(\mathbf{P h}-\mathbf{3 T} \text {-DCN-Hex })_{3}$ are the specific relative intensities of the reflections: second reflection (11) is 7.5 times stronger than the first one (10), and the third one (20) is of the same intensity $\left(I_{10}=I_{20}\right)$. Thus, with temperature increasing to $140{ }^{\circ} \mathrm{C}$ (Fig. S32, $\dagger$ curve 4), reflection 10 disappears while the other ones are still observed, and only at $160{ }^{\circ} \mathrm{C}$ isotropization 


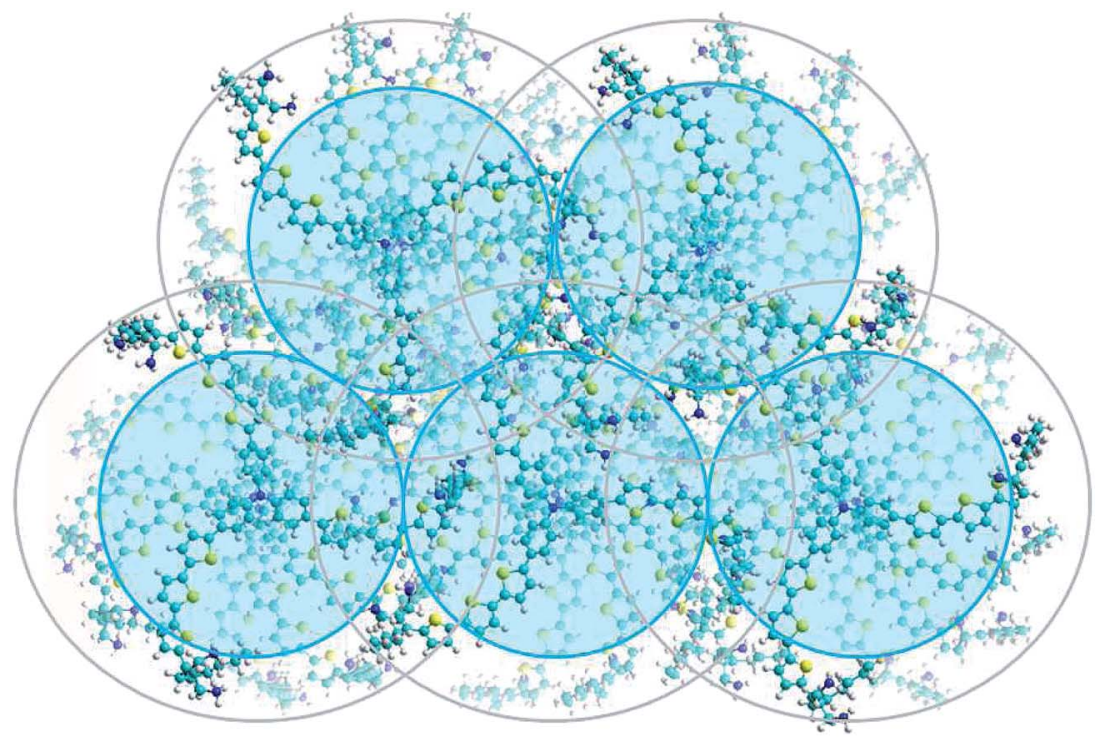

Fig. 4 Molecular modelling of the packing of $\mathrm{N}(\mathrm{Ph}-3 \mathrm{~T}-\mathrm{DCN}-\mathrm{Hex})_{3}$ molecules in 2D hexagonal columnar mesophase. Black solid circles correspond to 2D hexagonal columnar packing with the diameter of cylinders $D=23.7 \AA$. Grey solid are the envelopes of molecular discs $\left(D_{m}=30.6 \AA\right)$.

takes place (Fig. S32, $\dagger$ curve 5). Such observations can also be explained by a specific radial distribution of electron density in the cylinders of columnar mesophase leading to the shift of the position of the first diffraction peak to the minimum of Bessel function of an individual column. Thus, the composition of the column and lattice factors causes the intensity of 10 reflection to be substantially low. The columnar mesophase formed in the samples of N(Ph-3T-DCN-Hex $)_{3}$ looks to be very promising for the directed charge transport along the columns as the oligothiophene fragments of neighboring molecules are arranged to allow the best $\pi-\pi$ stacking. However, a good alignment of the columns is needed for the good semiconductor properties to manifest their selves. A separate work on the properties of oriented samples should be carried out.

Thin films formed by the mixtures of star-shaped molecules with $\mathrm{PC}_{71} \mathrm{BM}$ have also been studied using $\mathrm{X}$-ray reflectivity and Grazing Incidence X-ray reflectivity methods. Thickness of all blended films calculated from the positions of reflectivity minima (see Fig. S33†) is ca. $500 \AA$ A. Substantial roughness $2(\sim 5$ $\AA)$ of the surface of studied samples does not allow to provide unambiguous analysis of the distribution of electron density along the substrate director. Grazing incidence diffraction patterns (Fig. S34 $\dagger$ ) of all blends reveal three maxima at $s_{1}=$ $0.672 \AA^{-1}, s_{2}=1.346 \AA^{-1}$ and $s_{3}=1.957 \AA^{-1}$ corresponding to scattering from liquid-like phase of $\mathrm{PC}_{71} \mathrm{BM}\left(s_{1}: s_{2}: s_{3}=\right.$ $1: 2: 3$, curve 5 on Fig. S34 $\dagger$ ). The conclusion can be made that in blended films microsegregation takes place. Thiophenebased materials are amorphous, and $\mathrm{PC}_{71} \mathrm{BM}$ balls possess short-range order in their mutual arrangement.

\subsection{Film morphology}

Compared to their covalent polymeric counterparts, small molecules can significantly and directly influence many important material parameters such as solubility, crystallinity, phase behavior, microscopic morphology, which ultimately determine the device performance of OSCs. Normally, the size of crystalline domains in donor-acceptor films is one of the critical parameters determining device efficiency ${ }^{35}$ Therefore, to fabricate efficient $\mathrm{BHJ}$ solar cells using small molecules as donor materials, it is crucial to develop some methods of controlling its tendency to crystallize. In our previous study, modifying the alkyl solubilizing groups attached to the starshaped molecules appears to be an excellent approach to control the film morphology of the blend. ${ }^{16}$

Here, to further examine the effect of using these four starshaped molecules based on various $\pi$-bridge length on the film morphology of the blend, atomic force microscope (AFM) was employed to probe the film morphological properties. The topographic AFM images of the blended films determined by the optimized OSCs in ref. 16, are given in Fig. 5. All the blended films are rather smooth with an average surface roughness of $0.55 \mathrm{~nm}, 0.65 \mathrm{~nm}, 0.46 \mathrm{~nm}$ and $0.53 \mathrm{~nm}$ for N(Ph-1T-DCNMe $)_{3}: \mathrm{PC}_{71} \mathrm{BM}, \quad \mathbf{N}(\mathbf{P h}-2 \mathrm{~T}-\mathrm{DCN}-\mathrm{Me})_{3}: \mathrm{PC}_{71} \mathrm{BM}, \quad \mathbf{N}(\mathbf{P h}-2 \mathrm{~T}-\mathrm{DCN}-$ Hex $)_{3}: \mathrm{PC}_{71} \mathrm{BM}$, and N(Ph-3T-DCN-Hex $)_{3}: \mathrm{PC}_{71} \mathrm{BM}$ films, respectively. However, in all cases, the blend film morphologies were slightly different. It is evident from AFM studies that the variations in the molecular size and $\pi$-bridge length can cause changes in the microstructure of blended films. Quantitative investigation of the surface morphology based on the analysis of height correlation functions ${ }^{35-37}$ (see Fig. S35-S38†) revealed that N(Ph-2T-DCN-Me $)_{3}: \mathrm{PC}_{71} \mathrm{BM}, \quad$ and $\mathbf{N}(\mathbf{P h}-2 \mathrm{~T}-\mathbf{D C N}-$ Hex $)_{3}: \mathrm{PC}_{71} \mathrm{BM}$ blends are heterogeneous films. They are characterized by the two specific scales of the local and correlation length, one of them corresponding to the slope, diffuse blobs of the matter (supposedly, due to the phase segregation of the starlike compound and $\mathrm{PC}_{71} \mathrm{BM}$ ), and the other one ascribed to very high but extremely localized peaks. Contrary, the blends of 

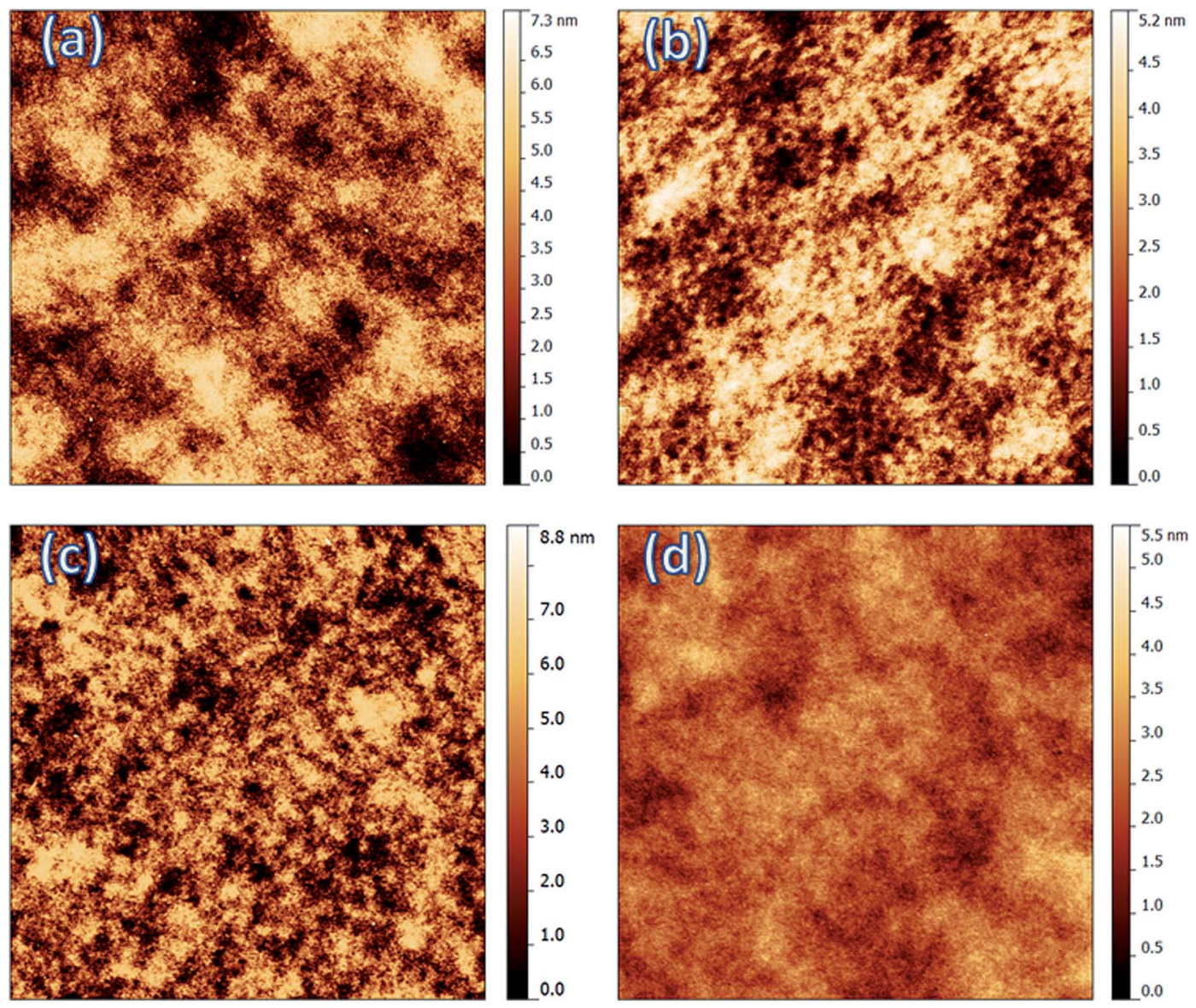

Fig. 5 Tapping mode AFM surface scans $\left(5 \times 5 \mu \mathrm{m}^{2}\right)$ of blended films without any thermal annealing of $(\mathrm{a}) \mathrm{N}(\mathrm{Ph}-1 \mathrm{~T}-\mathrm{DCN}-\mathrm{Me})_{3}: \mathrm{PC} \mathrm{C}_{71} \mathrm{BM},(\mathrm{b})$ $\mathrm{N}(\mathrm{Ph}-2 \mathrm{~T}-\mathrm{DCN}-\mathrm{Me})_{3}: \mathrm{PC}_{71} \mathrm{BM}$, (c) N(Ph-2T-DCN-Hex $)_{3}: \mathrm{PC}_{71} \mathrm{BM}$, and (d) N(Ph-3T-DCN-Hex $)_{3}: \mathrm{PC}_{71} \mathrm{BM}(\mathrm{D}: \mathrm{A} ; 1: 2 \mathrm{wt} \%)$.

N(Ph-1T-DCN-Me $)_{3}: \mathrm{PC}_{71} \mathrm{BM}$ and $\mathbf{N}(\mathbf{P h}-3 \mathrm{~T}-\mathrm{DCN}-\mathrm{Hex})_{3}: \mathrm{PC}_{71} \mathrm{BM}$ are more homogeneous and can be described by only one correlation length. These nanoscale aggregated domains are beneficial to the exciton charge separation, charge transportation and in turn enhance performance of the OSCs. ${ }^{\mathbf{1 6 , 3 8 - 4 0}}$ Therefore, judicious choice of an oligothiophene $\pi$-bridge at an appropriate length is of crucial importance for fine-tuning the structure-blended film morphology relationship.

\subsection{Hole mobility}

To further gain insight into the effect of $\pi$-bridges length within structurally well-defined star-shaped molecules on the charge transport, space charge limited current (SCLC) method was used to map out hole mobilities of the pristine and blended films. The structures of hole only devices were ITO/PEDOT:PSS/ pristine or blended films (D:A; $1: 2 \mathrm{wt} \%$ )/ $\mathrm{MoO}_{3} / \mathrm{Ag} .{ }^{16} \mathrm{We}$ calibrated the hole mobility $\left(\mu_{\mathrm{h}}\right)$ by fitting the current-voltage curves and measuring three different thicknesses of each films over eighteen diodes (Fig. S39-S41, ESI $\dagger$ ). As shown in Fig. S41, $\dagger$ the hole only mobilities of pristine and blended films just have moderate variations at different thicknesses of semiconductor layers. In addition, the charge carrier mobilities of blended films with $\mathrm{PC}_{71} \mathrm{BM}$ as acceptors exhibit a similar trend of the pristine TPA-based star shaped molecules. The results indicate a non-correlation between the charge carrier mobilities of pristine and blended films and the related films' thicknesses, and a correlation between the molecular physical properties and $\mathrm{BHJ}$ devices' transport properties. The related average values of hole mobilities of pristine and blended films are shown in Fig. 6 and Table 3. The pristine films in a range of film thicknesses for N(Ph-1T-DCN-Me $)_{3}, \mathbf{N}(\mathbf{P h}-\mathbf{2 T - D C N - M e})_{3}, \mathbf{N}(\mathbf{P h}-$ 2T-DCN-Hex $)_{3}$ and N(Ph-3T-DCN-Hex $)_{3}$ give hole only mobilities of $3.67 \times 10^{-5}, 3.99 \times 10^{-3}, 3.02 \times 10^{-4}$, and $6.40 \times 10^{-4} \mathrm{~cm}^{2}$ $\mathrm{V}^{-1} \mathrm{~s}^{-1}$, respectively. Obviously, N(Ph-1T-DCN-Me $)_{3}$ shows the lowest hole mobility in these pristine films, which is two orders of magnitude worse than that of N(Ph-2T-DCN-Me $)_{3}$. It suggests that a short $\pi$-conjugated thiophene bridge is not beneficial to the intramolecular electron transport, which can directly limit exciton diffusion and charge transport in OSCs. In addition, the hole mobility of N(Ph-2T-DCN-Hex $)_{3}$ is one order of magnitude worse than that of N(Ph-2T-DCN-Me $)_{3}$, which can most likely be attributed to weak conjugated backbone resulting from the long hexyl terminal chains. In order to compensate the negative effects of long terminal chains, introducing an electron linker to the conjugated main chains is also effective in maintaining a coplanar structure, and releasing the distortion induced by the alkyl terminal chains. Therefore, by further extending the 


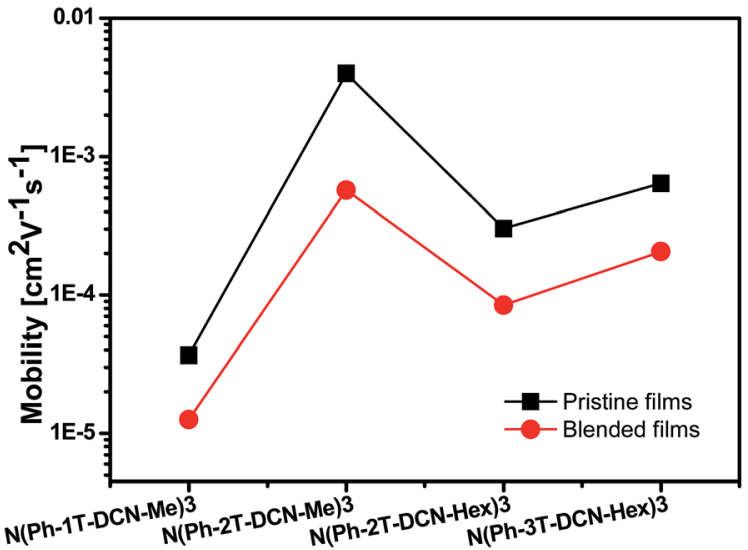

Fig. 6 Hole mobilities of pristine and blended films based on the four TPA-based molecules with an average value for a range of thicknesses.

$\pi$-conjugated bridges from bithiophene to terthiophene units and improving the bridge-planarization, the two times higher hole mobility measured in the $\mathbf{N}(\mathbf{P h}-\mathbf{3 T}-\mathbf{D C N}-\mathbf{H e x})_{3}$ diodes, as compared to that of N(Ph-2T-DCN-Hex $)_{3}$. It suggests that long $\pi$ conjugated terthiophene bridges can improve the bridge-planarization and facilitate intramolecular charge transport. However, it is interesting that the hole mobility of N(Ph-3TDCN-Hex $)_{3}$ is significantly lower than that of N(Ph-2T-DCN$\mathbf{M e})_{3}$, as shown in Fig. 6. This may be attributed to the twisted conjugated branch and reduced effective conjugated length caused by steric hindrance of long hexyl terminal chain. While this tendency of N(Ph-3T-DCN-Hex $)_{3}$ to give a low hole mobility in pristine film agrees well with the absorption measurements that N(Ph-3T-DCN-Hex $)_{3}$ has a relatively broad optical band gap.
Among the blended films with these four star-shaped molecules, N(Ph-2T-DCN-Me $)_{3}: \mathrm{PC}_{71} \mathrm{BM}$ exhibits the highest hole mobility of $5.72 \times 10^{-4} \mathrm{~cm}^{2} \mathrm{~V}^{-1} \mathrm{~s}^{-1}, 45$ times higher than that of N(Ph-1T-DCN-Me $)_{3}: \mathrm{PC}_{71} \mathrm{BM}$. The high hole mobility of $\mathbf{N}(\mathbf{P h}-2 \mathrm{~T}-\mathbf{D C N}-\mathbf{M e})_{3}: \mathrm{PC}_{71} \mathrm{BM}$, which arose from the longer conjugation length along the molecule, is promising with respect of enhanced photocurrent generation and reduced recombination loss. In addition, the hole mobilities of $\mathbf{N}(\mathbf{P h}-2 \mathbf{T}-$ DCN-Hex $)_{3}: \mathrm{PC}_{71} \mathrm{BM}$ and $\mathbf{N}(\mathbf{P h}-3 \mathrm{~T}-\mathrm{DCN}-\mathrm{Hex})_{3}: \mathrm{PC}_{71} \mathrm{BM}$ are 8.45 $\times 10^{-5}$ and $2.06 \times 10^{-4} \mathrm{~cm}^{2} \mathrm{~V}^{-1} \mathrm{~s}^{-1}$, respectively, which is consistent with the hole mobilities of the pristine films. These results illustrate that intramolecular charge transfer instead of intermolecular transport in small molecule domains plays a decisive role for the charge transport of blended film. Therefore, we expect that these differences in film morphology and charge transport in blended films will have a significant impact on the device performance as discussed below.

\subsection{Photovoltaic properties of $\mathrm{BHJ}$ devices based on these compounds}

To study the effect of oligothiophene $\pi$-bridge length on the photovoltaic properties, bulk heterojunction OSCs with a configuration of ITO/PEDOT:PSS/TPA-based molecules: $\mathrm{PC}_{71} \mathrm{BM}$ $(1: 2$, wt $\%) / \mathrm{Ca}(15 \mathrm{~nm}) / \mathrm{Ag}(80 \mathrm{~nm})$ were fabricated, and the detailed device fabrication process is described in the Experimental section. The best current density-voltage $(J-V)$ curves are shown in Fig. 7a and the corresponding photovoltaic performance is summarized in Table 4.

As expected, OSCs based on these small molecules show relatively high $V_{\mathrm{oc}}(>0.9 \mathrm{~V})$, due to their low-lying HOMO energy levels. Encouragingly, OSC based on N(Ph-1T-DCN-Me) ${ }_{3}$

Table 3 Hole mobilities determined from the SCLC measurements

\begin{tabular}{lllll}
\hline Molecules & $\begin{array}{l}\text { Thicknesses of } \\
\text { pristine films }(\mathrm{nm})\end{array}$ & $\begin{array}{l}\text { Hole mobility }{ }^{a}\left(\mu_{\mathrm{h}}\right) \\
{\left[\mathrm{cm}^{2} \mathrm{~V}^{-1} \mathrm{~s}^{-1}\right]}\end{array}$ & $\begin{array}{l}\text { Thicknesses of } \\
\text { blended films }(\mathrm{nm})\end{array}$ & $\begin{array}{l}\text { Hole mobility } \\
{\left[\mathrm{cm}^{2} \mathrm{~V}^{-1} \mathrm{~s}^{-1}\right]}\end{array}$ \\
\hline $\mathbf{N}(\mathbf{P h}-\mathbf{h} \text {-DCN-Me })_{3}$ & $100 / 160 / 190$ & $3.67 \times 10^{-5}$ & $60 / 90 / 130$ & $1.26 \times 10^{-5}$ \\
$\mathbf{N}(\mathbf{P h}-2 \text { T-DCN-Me })_{3}$ & $80 / 130 / 180$ & $3.99 \times 10^{-3}$ & $70 / 100 / 120$ & $5.72 \times 10^{-4}$ \\
$\mathbf{N}(\mathbf{P h}-2 \text { T-DCN-Hex })_{3}$ & $90 / 140 / 190$ & $3.02 \times 10^{-4}$ & $70 / 90 / 110$ & $8.45 \times 10^{-5}$ \\
$\mathbf{N}(\mathbf{P h}-3 \text { T-DCN-Hex })_{3}$ & $90 / 130 / 200$ & $6.40 \times 10^{-4}$ & $60 / 80 / 110$ & $2.06 \times 10^{-4}$
\end{tabular}

${ }^{a}$ The reported mobility data are average values of each pristine and blended films for a range of thicknesses.
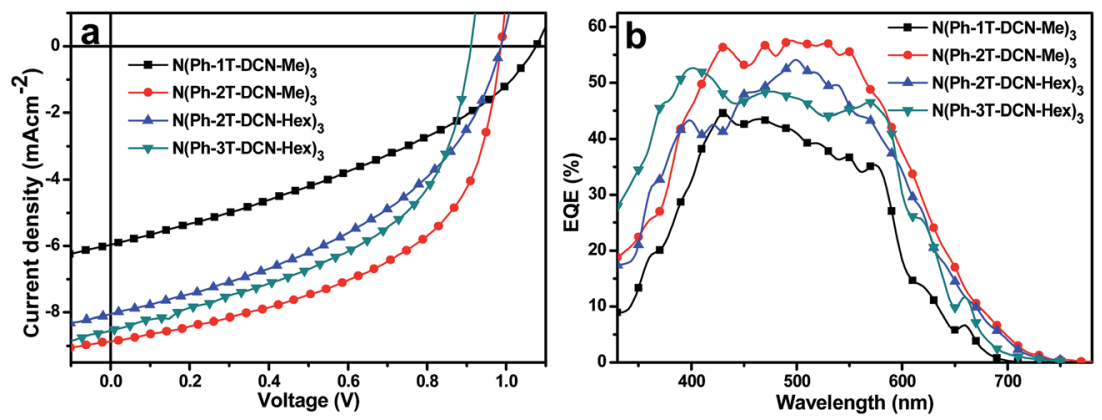

Fig. 7 Current density-voltage $\left(I-V\right.$ ) curves (a) and EQE spectra (b) of solar cells based on N(Ph-1T-DCN-Me) $3: P C_{71} B M, N(P h-2 T-D C N-$ $\mathrm{Me})_{3}: \mathrm{PC}_{71} \mathrm{BM}, \mathrm{N}(\mathrm{Ph}-2 \mathrm{~T}-\mathrm{DCN}-\mathrm{Hex})_{3}: \mathrm{PC}_{71} \mathrm{BM}$, and $\mathrm{N}(\mathrm{Ph}-3 \mathrm{~T}-\mathrm{DCN}-\mathrm{Hex})_{3}: \mathrm{PC}_{71} \mathrm{BM}(1: 2, \mathrm{wt} \%)$, respectively, under the illumination of $\mathrm{AM} 1.5$, $100 \mathrm{~mW} \mathrm{~cm}^{-2}$. 
Table 4 Photovoltaic properties of star-shaped molecules: $\mathrm{PC}_{71} \mathrm{BM}$ $\left(1: 2\right.$, wt\%) devices, under the illumination of $A M 1.5,100 \mathrm{~mW} \mathrm{~cm}^{-2}$

\begin{tabular}{|c|c|c|c|c|}
\hline Donor: $\mathrm{PC}_{71} \mathrm{BM}$ & $V_{\text {oc }}(\mathrm{V})$ & $J_{\mathrm{sc}}\left(\mathrm{mA} \mathrm{cm}{ }^{-2}\right)$ & $\mathrm{FF}(\%)$ & PCE (\%) \\
\hline N(Ph-1T-DCN-Me $)_{3}$ & 1.08 & 5.97 & 35.6 & 2.30 \\
\hline $\mathbf{N}(\mathbf{P h}-2 \mathrm{~T}-\mathrm{DCN}-\mathrm{Me})_{3}$ & 0.98 & 8.87 & 54.3 & 4.72 \\
\hline $\mathrm{N}(\mathrm{Ph}-2 \mathrm{~T}-\mathrm{DCN}-\mathrm{Hex})_{3}$ & 0.98 & 8.07 & 43.1 & 3.41 \\
\hline $\mathrm{N}(\mathrm{Ph}-3 \mathrm{~T}-\mathrm{DCN}-\mathrm{Hex})_{3}$ & 0.93 & 8.51 & 50.0 & 3.96 \\
\hline
\end{tabular}

exhibited a high $V_{\text {oc }}$ up to $1.08 \mathrm{~V}$. With the increasing $\pi$-conjugated oligothiophene bridge length, OSCs based on N(Ph-2TDCN-Me $)_{3} / \mathbf{N}(\mathbf{P h}-2 \text { T-DCN-Hex })_{3}$ and $\mathbf{N}(\mathbf{P h}-3 \mathrm{~T}-\mathrm{DCN}-\mathrm{Hex})_{3}$ showed the lower $V_{\mathrm{oc}}$ of $0.98 / 0.98 \mathrm{~V}$ and $0.93 \mathrm{~V}$, respectively. These results are consistent with their HOMO level variations (Table 2). Simultaneously, OSCs based on N(Ph-1T-DCN-Me $)_{3}, \mathbf{N}(\mathbf{P h}-2 \mathrm{~T}-$ DCN-Me $)_{3}, \quad$ N(Ph-2T-DCN-Hex $)_{3}, \quad$ and $\quad$ N(Ph-3T-DCN-Hex $)_{3}$ provide a $J_{\mathrm{sc}}$ of $5.97 \mathrm{~mA} \mathrm{~cm}^{-2}, 8.87 \mathrm{~mA} \mathrm{~cm}^{-2}, 8.07 \mathrm{~mA} \mathrm{~cm}^{-2}$, and $8.51 \mathrm{~mA} \mathrm{~cm}^{-2}$, respectively, which correlates with the trend in their absorption spectra, optical band gaps and transport properties. The FF exhibits the similar trends of $J_{\mathrm{sc}}$, as shown in Table 4. Absorption spectra and electronic structure of the components are obviously important for device operation, but the role of film morphology cannot be ignored, since the charge separation takes place at the donor-acceptor interface. As discussed, we found that the changes in the $J_{\mathrm{sc}}$ and $\mathrm{FF}$ values of the devices are also consistent with both changes in the film morphologies as well as the hole mobilities. In the case of $\mathbf{N}(\mathbf{P h}-$ 1T-DCN-Me $)_{3}: \mathrm{PC}_{71} \mathrm{BM}$ device, both poor film quality and the charge transport result in a significant drop in the $J_{\mathrm{sc}}$ and $\mathrm{FF}$, as shown in Fig. 5a and 6. This is attributed to strong recombination losses, presumably because of the inferior hole mobility of the active layer. In contrast, the $\mathbf{N}(\mathbf{P h}-2 \mathrm{~T}-\mathbf{D C N}-\mathbf{M e})_{3}: \mathrm{PC}_{71} \mathrm{BM}$ device exhibits an increased $J_{\mathrm{sc}}$ of $8.87 \mathrm{~mA} \mathrm{~cm} \mathrm{~cm}^{-2}$ and an improved FF of $54.3 \%$, mainly due to a higher hole mobility and a better charge collection as a result of the effective conjugated length in the molecule and formation of nanoscale domains in the active layer. In addition, compared to N(Ph-2T-DCNHex $)_{3}: \mathrm{PC}_{71} \mathrm{BM}$ device, a slightly higher $J_{\mathrm{sc}}$ of $8.51 \mathrm{~mA} \mathrm{~cm}{ }^{-2}$ and a $\mathrm{FF}$ of $50 \%$ are observed for the N(Ph-3T-DCN-Hex $)_{3}: \mathrm{PC}_{71} \mathrm{BM}$ device, which is again attributed to a favorable film morphology as well as high hole mobility. Finally, the PCEs of these devices are $2.30 \%$ for N(Ph-1T-DCN-Me $)_{3}, 4.72 \%$ for N(Ph-2T-DCN-Me $)_{3}$, $3.41 \%$ for N(Ph-2T-DCN-Hex $)_{3}$ and $3.96 \%$ for N(Ph-3T-DCN$\mathrm{Hex}_{3}$, respectively. The external quantum efficiency (EQE) of the corresponding devices is shown in Fig. $7 \mathrm{~b}, J_{\mathrm{sc}}$ calculated from the EQE is $5.46 \mathrm{~mA} \mathrm{~cm}^{-2}$ for N(Ph-1T-DCN-Me $)_{3}, 8.27 \mathrm{~mA} \mathrm{~cm}^{-2}$ for N(Ph-2T-DCN-Me $)_{3}, 7.53 \mathrm{~mA} \mathrm{~cm}{ }^{-2}$ for N(Ph-2T-DCN-Hex $)_{3}$, and $7.76 \mathrm{~mA} \mathrm{~cm}{ }^{-2}$ for $\mathbf{N}(\mathbf{P h}-\mathbf{3 T}-\mathbf{D C N}-\mathbf{H e x})_{3}$, respectively, well consistent with the values of $J_{\mathrm{sc}}$ measured under simulated AM 1.5.

\section{Conclusions}

In summary, the effects of oligothiophene $\pi$-bridge length on the properties of star-shaped molecules were evaluated by comparing four TPA-containing compounds with different $\pi$-bridge lengths. Material physical properties of the four compounds revealed that the oligothiophene $\pi$-bridges between $\mathrm{D}$ and $\mathrm{A}$ units have a significant impact on intramolecular and intermolecular interactions, which subsequently affect various solid-state properties such as film absorption, blend morphology and charge carrier mobility, thereby influencing the photovoltaic properties of devices. Within this series, $\mathbf{N}(\mathbf{P h}-2 \mathrm{~T}-\mathrm{DCN}-\mathrm{Me})_{3}$ shows the highest performance among the four compounds due to the broader absorption and higher hole mobilities in pristine and blend films. Therefore, the utility of conjugation length engineering on small molecules is of crucial importance to elucidate structure-property relationships. Insight into such relationships will be beneficial for the judicious choice of new molecules based on appropriate conjugation length for use in organic photovoltaics as well as other electronic devices.

\section{Experimental section}

\subsection{Materials}

$n$-Butyl lithium (1.6 M solution in hexane), magnesium, isopropoxy-4,4,5,5-tetramethyl-1,3,2-dioxaborolane (IPTMDOB), tetrakis(triphenylphosphine)palladium $(0) \operatorname{Pd}\left(\mathrm{PPh}_{3}\right)_{4}, p$-toluenesulfonic acid ( $p$-TosH), tris(4-bromophenyl)amine, malononitrile, heptanoyl chloride, acetyl chloride, 2,2-dimethyl-1,3propanediol, 2-bromothiophene were obtained from SigmaAldrich Co. and used without further purification. THF, benzene, pyridine and ethylene glycol were dried and purified according to the known techniques and then used as solvents. 5-Bromo-2, $2^{\prime}: 5^{\prime}, 2^{\prime \prime}$-terthiophene was obtained as described in ref. 41. $\mathrm{Li}_{2} \mathrm{MnCl}_{4}$ was obtained as described in ref. 42 . All reactions, unless stated otherwise, were carried out under an inert atmosphere.

\subsection{Characterization}

GPC analysis was performed by means of a Shimadzu LC10A ${ }^{\mathrm{VP}}$ series chromatograph (Japan) equipped with an RID- $10 \mathrm{~A}^{\mathrm{VP}}$ refractometer and SPD-M10A ${ }^{\mathrm{VP}}$ diode matrix as detectors and a Phenomenex column (USA) with a size of $7.8 \times 300 \mathrm{~mm}^{2}$ filled with the Phenogel sorbent with a pour size of $500 \AA$; THF was used as the eluent. For thin layer chromatography, "Sorbfil" (Russia) plates were used. In the case of column chromatography, silica gel 60 ("Merck") was taken. ${ }^{1} \mathrm{H}$ NMR spectra were recorded at a "Bruker WP-250 SY "spectrometer, working at a frequency of $250.13 \mathrm{MHz}$ and utilising $\mathrm{CDCl}_{3}$ signal (7.25 ppm) as the internal standard. ${ }^{13} \mathrm{C}$ NMR spectra were recorded using a "Bruker Avance II 300" spectrometer at $75 \mathrm{MHz}$ and Bruker DRX500 at $125 \mathrm{MHz}$. In the case of ${ }^{1} \mathrm{H}$ NMR spectroscopy, the compounds to be analysed were taken in the form of $1 \%$ solutions in $\mathrm{CDCl}_{3}$. In the case of ${ }^{13} \mathrm{C}$ NMR spectroscopy, the compounds to be analysed were taken in the form of $5 \%$ solutions in $\mathrm{CDCl}_{3}$. The spectra were then processed on the computer using the ACD Labs software. High resolution mass spectra (HR MS) were measured on a Bruker micro TOF II instrument using electrospray ionization (ESI). The measurements were done in a positive ion mode (interface capillary 
voltage $-4500 \mathrm{~V})$ or in a negative ion mode $(3200 \mathrm{~V})$; mass range from $\mathrm{m} / \mathrm{z} 50$ to $\mathrm{m} / \mathrm{z} 3000 \mathrm{Da}$; external or internal calibration was done with Electrospray Calibrant Solution (Fluka). A syringe injection was used for solutions in acetonitrile, methanol, or water (flow rate $3 \mu \mathrm{L} \mathrm{min}{ }^{-1}$ ). Nitrogen was applied as a dry gas; interface temperature was set at $180{ }^{\circ} \mathrm{C}$. Mass-spectra (MALDI) were registered on the Autoflex II Bruker (resolution FWHM 18000), equipped with nitrogen laser (work wavelength $337 \mathrm{~nm}$ ) and time-of-flight mass-detector working in reflections mode. The accelerating voltage was $20 \mathrm{kV}$. Samples were applied to a polished stainless steel substrate. Spectrum was recorded in the positive ion mode. The resulting spectrum was the sum of 300 spectra obtained at different points of sample. 2,5-Dihydroxybenzoic acid (DHB) (Acros, 99\%) and $\alpha$-cyano-4-hydroxycinnamic acid (HCCA) (Acros, 99\%) were used as matrices. Elemental analysis of $\mathrm{C}, \mathrm{H}, \mathrm{N}$ elements was carried out using CHN automatic analyzer CE 1106 (Italy). The settling titration using $\mathrm{BaCl}_{2}$ was applied to analyze sulphur. Experimental error is $0.30-0.50 \%$. The Knövenagel condensation was carried out in the microwave "Discovery", (CEM corporation, USA), using a standard method with the open vessel option, 50 watts. Thermogravimetric analysis was carried out in dynamic mode in 30/ $900{ }^{\circ} \mathrm{C}$ interval using Mettler Toledo TG50 system equipped with M3 microbalance allowing measuring the weight of samples in 0-150 $\mathrm{mg}$ range with $1 \mu \mathrm{g}$ precision. Heating/cooling rate was chosen to be $10{ }^{\circ} \mathrm{C} \mathrm{min}^{-1}$. Every compound was studied twice: in air and in nitrogen flow of $200 \mathrm{~mL} \mathrm{~min}^{-1}$. DSC scans were obtained with Mettler Toledo DSC30 system with $20{ }^{\circ} \mathrm{C}$ $\mathrm{min}^{-1}$ heating/cooling rate in temperature range of $+20 / 250{ }^{\circ} \mathrm{C}$

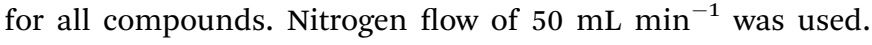
Absorption profiles were recorded with a Perkin Elmer Lambda35 absorption spectrometer from 350 to $1100 \mathrm{~nm}$. Electrochemical properties were studied by cyclic voltammetry (CVA). The measurements were carried out in the 1,2-dichlorobenzene-acetonitrile $(4: 1)$ mixture of solvents using $0.1 \mathrm{M}$ $\mathrm{Bu}_{4} \mathrm{NPF}_{6}$ as supporting electrolyte. The glassy carbon electrode was used as a work electrode. Potentials were measured relative to a saturated calomel electrode.

\subsection{X-ray diffraction}

$\mathrm{X}$-ray diffraction patterns in small and wide angle scattering regions were recorded by $\mathrm{S} 3$-Micropix system (Hecus company), $\mathrm{CuK}_{\alpha}$-radiation, $\lambda=1.5406 \AA$ with Xenocs Genix source (voltage and current - $50 \mathrm{kV}$ and $1 \mathrm{~mA}$ respectively). Pilatus $100 \mathrm{~K}$ detector was employed, as well as linear PSD 50M gas detector (Ar/Me mixture at $8 \times 10^{5} \mathrm{~Pa}$ ). Collimation system Fox 3D with Kratky collimation slits of $0.1 \mathrm{~mm}$ and $0.2 \mathrm{~mm}$ width was used, allowing the stable measurements in wave vector range from $s=0.003 \AA^{-1}$ to $s=1.9 \AA^{-1}$ where $s=4 \pi \sin \theta / \lambda, 2 \theta$ is scattering angle. To get rid of the scattering of X-rays on air molecules, Goebbel mirrors and scattering path are vacuumed at pressures 2.6/5.0 Pa. Exposure times were from 600 to $5000 \mathrm{~s}$ providing the high reliability of scattering data. Temperature behavior of samples was studied using Joule attachment in temperature range of $23-300{ }^{\circ} \mathrm{C}$. Transmission X-ray diffraction patterns at wide angles were also recorded at Bruker D8 Advance powder diffractometer ( $\mathrm{CuK}_{\alpha}$-radiation, $\lambda=1.5406 \AA$, Vantec $2 \mathrm{D}$ detector). Accelrys Materials Studio® program set was employed for molecular modeling of compounds studied. We used two sets of potentials, which allow taking into account non-covalent interactions: COMPASS (Condensed-phase Optimized Molecular Potentials for Atomistic Simulation Studies) and UFF (Universal Force Field). The COMPASS set is suitable for modeling of isolated molecules and condensed phases of mainly organic, polymeric and of some inorganic compounds, ${ }^{43-45}$ it also allows to parametrize partial charges and valency $a b$ initio with subsequent system optimization. To prove the results of modelling, we applied UFF potentials as it does not have any limitation on the chemistry of compounds involved. ${ }^{\mathbf{4 6 - 4 8}}$ Grazing incidence X-ray diffraction and X-ray reflectivity experiments were performed on DESY synchrotron radiation source (Hamburg, Germany), using PETRA III P-09 beamline. Incident X-ray beam with the energy of $15 \mathrm{keV}$ probed compounds' films had the size of $200 \mu \mathrm{m}$ and $50 \mu \mathrm{m}$ in vertical and horizontal directions respectively. Reflected radiation was monitored by 2D Perkin Elmer 1621 CN3-ETIS detector as well as by point avalanche photodiode recorder. During the experiment, samples were kept under helium atmosphere to reduce radiation damage. X-ray reflectivity data were analyzed using StochFit program which utilizes stochastic fitting methods to model specular reflectivity curves. The obtained distributions of electron density were afterwards interpolated by slab models with subsequent solution of scattering problem and following reconstruction of reflectivity curves. The electron density $\rho=2 \pi \delta / \lambda^{2} \gamma_{\mathrm{e}}$ where $\gamma_{\mathrm{e}}$ is the classical electron radius equal to $2.814 \times 10^{-5} \AA$, and $\delta$ is the dispersion coefficient, ${ }^{49}$ as well as thickness $d$ and roughness $R$ of monolayers were calculated.

\subsection{Fabrication and characterization of the OSCs}

All the devices were fabricated in the normal architecture. Photovoltaic devices were fabricated by doctor-blading on indium tin oxide (ITO)-covered glass substrates (from Osram). These substrates were cleaned in toluene, water, acetone, and isopropyl alcohol. After drying, the substrates were bladed with 50 nm PEDOT:PSS (HC Starck, PEDOT PH-4083). Photovoltaic layers, consisting of three different small molecules and $\mathrm{PC}_{71} \mathrm{BM}$ in $1: 2 \mathrm{wt} \%$ ratios were dissolved at different concentrations in ODCB and bladed on top of PEDOT:PSS layer. Finally, a calcium/silver top electrode of 15/80 nm thickness was evaporated. The typical active area of the investigated devices was $10.4 \mathrm{~mm}^{2}$. The current-voltage characteristics of the solar cells were measured under AM 1.5G irradiation on an OrielSol 1A Solar simulator $\left(100 \mathrm{~mW} \mathrm{~cm}^{-2}\right)$. The EQE was detected with cary 500 Scan UV-vis-NIR Spectrophotometer under monochromatic illumination, which was calibrated with a monocrystalline silicon diode. Absorption profiles were recorded with a Perkin Elmer Lambda-35 absorption spectrometer from 350 to 1100. AFM measurements were performed with a Nanosurf Easy Scan 2 in contact mode. Single carrier devices were fabricated and the dark current-voltage characteristics measured and analyzed in the space charge limited (SCL) regime following the ref. 16. The structure of hole only devices was Glass/ITO/ 
PEDOT:PSS/Active layer/ $\mathrm{MoO}_{3} / \mathrm{Ag}(100 \mathrm{~nm})$. The reported mobility data are average values of eighteen devices of each pristine and blended films for a range of thicknesses.

\section{Acknowledgements}

The authors gratefully acknowledge the support of the Cluster of Excellence "Engineering of Advanced Materials" at the University of Erlangen-Nuremberg, which is funded by the German Research Foundation (DFG) within the framework of its "Excellence Initiative". We are also grateful for support at beamline P09 at Petra III DESY synchrotron source. This work has been partially funded by the Sonderforschungsbereich 953 "Synthetic Carbon Allotropes", Solar Technologies go Hybrid (SolTech), the China Scholarship Council (CSC). This work was also partially supported by the Ministry of Education and Science of the Russian Federation (11.G34.31.0055), the Program of President of Russian Federation for Support of Young Scientists (grant MK-6716.2013.3) and Presidium of Russian Academy of Sciences (Program P-8).

\section{References}

1 C. J. Brabec, N. S. Sariciftci and J. C. Hummelen, Adv. Funct. Mater., 2001, 11, 15-26.

2 G. Yu, J. Gao, J. C. Hummelen, F. Wudl and A. J. Heeger, Science, 1995, 270, 1789-1791.

3 J. Min, Z. G. Zhang, S. Y. Zhang and Y. F. Li, Chem. Mater., 2012, 24, 3247-3254.

4 J. Y. Zhou, Y. Zou, X. J. Wan, G. K. Long, Q. Zhang, W. Ni, Y. S. Liu, Z. Li, G. R. He, C. X. Li, B. Kan, M. M. Li and Y. S. Chen, J. Am. Chem. Soc., 2013, 135, 8484-8487.

5 J. H. Liu, B. Walker, A. Tamayo, Y. Zhang and T. Q. Nguyen, Adv. Funct. Mater., 2013, 23, 47-56.

6 V. Gupta, A. K. K. Kyaw, D. H. Wang, S. Chand, G. C. Bazan and A. J. Heeger, Sci. Rep., 2013, 3, 1965.

7 A. K. K. Kyaw, D. H. Wang, V. Gupta, W. L. Leong, L. Ke, G. C. Bazan and A. J. Heeger, ACS Nano, 2013, 7, 4569-4577.

8 P. Dutta, W. Yang, W. H. Lee, I. N. Kang and S. H. Lee, J. Mater. Chem., 2012, 22, 10840-10851.

9 W. W. Li, M. Kelchtermans, M. M. Wienk and R. A. J. Janssen, J. Mater. Chem. A, 2013, 1, 15150-15157.

10 B. Walker, C. Kim and T. Q. Nguyen, Chem. Mater., 2011, 23, 470-482.

11 B. Walker, A. B. Tamayo, X.-D. Dang, P. Zalar, J. H. Seo, A. Garcia, M. Tantiwiwat and T.-Q. Nguyen, Adv. Funct. Mater., 2009, 19, 3063-3069.

12 J.-Y. Pan, L.-J. Zou, X.-L. Hu, W.-F. Fu, M.-R. Chen, L. Fu, X. Gu, H.-Q. Shi, M.-M. Shi, H.-Y. Li and H.-Z. Chen, ACS Appl. Mater. Interfaces, 2013, 5, 972-980.

13 Y. Z. Lin, L. C. Ma, Y. F. Li, Y. Q. Liu, D. B. Zhu and X. W. Zhan, Adv. Energy Mater., 2013, 3, 1166-1170.

14 Y. S. Liu, C.-C. Chen, Z. R. Hong, J. Gao, Y. (Michael) Yang, H. P. Zhou, L. T. Dou, G. Li and Y. Yang, Sci. Rep., 2013, 3, 3356.
15 S. Loser, H. Miyauchi, J. W. Hennek, J. Smith, C. Huang, A. Facchetti and T. J. Marks, Chem. Commun., 2012, 48, 8511-8513.

16 J. Min, Y. N. Luponosov, A. Gerl, M. S. Polinskaya, S. M. Peregudova, P. V. Dmitryakov, A. V. Bakirov, M. A. Shcherbina, S. N. Chvalun, S. Grigorian, N. K. Busies, S. A. Ponomarenko, T. Ameri and C. J. Brabec, Adv. Energy Mater., 2014, 4, 1301234.

17 J. Min, Y. N. Luponosov, T. Ameri, A. Elschner, S. M. Peregudova, D. Baran, T. Heumüller, N. Li, F. Machui, S. Ponomarenko and C. J. Brabec, Org. Electron., 2013, 14, 219-225.

18 E. Ripaud, T. Rousseau, P. Leriche and J. Roncali, Adv. Energy Mater., 2011, 1, 540-545.

19 S. Roquet, A. Cravino, P. Leriche, O. Aleveque, P. Frere and J. Roncali, J. Am. Chem. Soc., 2006, 128, 3459-3466.

20 H. Bürckstümmer, E. V. Tulyakova, M. Deppisch, M. R. Lenze, N. M. Kronenberg, M. Gsänger, M. Stolte, K. Meerholz and F. Würthner, Angew. Chem., Int. Ed., 2011, 50, 11628-11632.

21 X. Yang, S. C. Veenstra, W. J. H. Verhees, M. M. Wienk, R. A. J. Janssen, J. M. Kroon, M. A. J. Michels and J. Loos, Nano Lett., 2005, 5, 579-583.

22 D. Demeter, V. Jeux, P. Leriche, P. Blanchard, Y. Olivier, J. Cornil, R. Po and J. Roncali, Adv. Funct. Mater., 2013, 23, 4854-4861.

23 (a) C. H. Cui, J. Min, C. L. Ho, T. Ameri, P. Yang, J. Z. Zhao, C. J. Brabec and W. Y. Wong, Chem. Commun., 2013, 49, 4409-4411; (b) S. L. Shen, P. Jiang, C. He, J. Zhang, P. Shen, Y. Zhang, Y. P. Yi, Z. J. Zhang, Z. B. Li and Y. F. Li, Chem. Mater., 2013, 25, 2274-2281.

24 X. F. Liu, Y. M. Sun, L. A. Perez, W. Wen, M. F. Toney, A. J. Heeger and G. C. Bazan, J. Am. Chem. Soc., 2012, 134, 20609-20612.

25 P. C. Li, H. Tong, J. Q. Ding, Z. Y. Xie and L. X. Wang, J. Mater. Chem. A, 2013, 1, 8805-8812.

26 J. Roncali, Acc. Chem. Res., 2009, 42, 1719-1730.

27 E. Ripaud, T. Rousseau, P. Leriche and J. Roncali, Adv. Energy Mater., 2011, 1, 540-545.

28 S. Roquet, A. Cravino, P. Leriche, O. Aleveque, P. Free and J. Roncali, J. Am. Chem. Soc., 2006, 128, 3459-3466.

29 A. Cravino, P. Leriche, O. Aleveque, S. Roquet and J. Roncali, Adv. Mater., 2006, 18, 3033-3037.

30 A. Cravino, S. Roquet, P. Leriche, O. Alévêque, P. Frère and J. Roncali, Chem. Commun., 2006, 1416-1418.

31 J. Zhang, D. Deng, C. He, Y. J. He, M. J. Zhang, Z. G. Zhang, Z. J. Zhang and Y. F. Li, Chem. Mater., 2011, 23, 817-822.

32 P. A. Troshin, H. Hoppe, J. Renz, M. Egginger, J. Y. Mayorova, A. E. Goryachev, A. S. Peregudov, R. N. Lyubovskaya, G. Gobsch, N. S. Sariciftci and V. F. Razumov, Adv. Funct. Mater., 2009, 19, 779-788.

33 P. J. Brown, D. S. Thomas, A. Köhler, J. S. Wilson, J. S. Kim, C. M. Ramsdale, H. Sirringhaus and R. H. Friend, Phys. Rev. B: Condens. Matter Mater. Phys., 2003, 67, 642031.

34 S. A. Ponomarenko, N. N. Rasulova, Y. N. Luponosov, N. M. Surin, M. I. Buzin, I. Leshchiner, S. M. Peregudova and A. M. Muzfarov, Macromolecules, 2012, 45, 2014. 
35 P. Meakin, Fractals, scaling and growth far from equilibrium, Cambridge University Press, 1998.

36 Y. Zhao, G.-C. Wang and T.-M. Lu, Characterization of amorphous and crystalline rough surface: principles and applications, Academic Press, 2001.

37 D. R. Streltsov, A. I. Buzin, E. I. Grigoriev, P. V. Dmitryakov, K. A. Mailyan and S. N. Chvalun, Nanotechnologies in Russia, 2008, 3, 494.

38 (a) J. Min, Z. G. Zhang, M. J. Zhang and Y. F. Li, Polym. Chem., 2013, 4, 1467; (b) Y. Z. Lin, P. Cheng, Y. Liu, Q. Q. Shi, W. P. Hu, Y. F. Li and X. W. Zhan, Org. Electron., 2012, 13, 673-680.

39 A. Tamayo, T. Kent, M. Tantitiwat, M. A. Dante, J. Rogers and T.-Q. Nguyen, Energy Environ. Sci., 2009, 2, 1180-1186.

40 C. J. Brabec, A. Cravino, D. Meissner, N. S. Sariciftci, T. Fromherz, M. T. Rispens, L. Sanchez and J. C. Hummelen, Adv. Funct. Mater., 2001, 11, 374-380.
41 M. Melucci, G. Barbarella, M. Zambianchi, P. Di Pietro and A. Bongini, J. Org. Chem., 2004, 69, 4821-4828.

42 G. Cahiez and B. Laboue, Tetrahedron Lett., 1992, 33, 44394442.

43 H. Sun, J. Phys. Chem. B, 1998, 102, 7338-7364.

44 H. Sun, Comput. Theor. Polym. Sci., 1998, 8, 229-246.

45 D. Rigby, H. Sun and B. E. Eichinger, Polym. Int., 1998, 44, 311-330.

46 A. K. Rappe, C. J. Casewit, K. S. Colwell, W. A. Goddard and W. M. Skiff, J. Am. Chem. Soc., 1992, 114, 10024-10035.

47 C. J. Casewit, K. S. Colwell and A. K. Rappe, J. Am. Chem. Soc., 1992, 114, 10035-10046.

48 A. K. Rappe, K. S. Colwell and C. J. Casewit, Inorg. Chem., 1993, 32, 3438-3450.

49 N. A. Kotov, F. C. Meldrum, J. H. Fendler, E. Tombacz and I. Dekany, Langmuir, 1994, 10, 3797-3804. 